alopecia as an early marker of benign prostatic hyperplasia. Acta Derm Venereol 2010;90:485-487.

7. Weilner S, Skalicky S, Salzer B, Keider V, Wagner M, Hildner $F$, et al. Differentially circulating miRNAs after recent osteoporotic fractures can influence osteogenic differentiation. Bone 2015;79:43-51.

8. Aslam A, Salam A, Griffiths CE, McGrath JA. Naevus sebaceus: a mosaic RASopathy. Clin Exp Dermatol 2014;39:
$1-6$.

9. Tsai JH, Huang WC, Jhuang JY, Jeng YM, Cheng ML, Chiu $\mathrm{HY}$, et al. Frequent activating HRAS mutations in trichilemmoma. Br J Dermatol 2014;171:1073-1077.

10. Golomb L, Sagiv A, Pateras IS, Maly A, Krizhanovsky V, Gorgoulis VG, et al. Age-associated inflammation connects RAS-induced senescence to stem cell dysfunction and epidermal malignancy. Cell Death Differ 2015;22:1764-1774.

\title{
Multiple Basal Cell Carcinomas with Infundibular Structures and Trichoblastoma
}

\author{
Kohei Kato, Takeshi Namiki, Rana Kawai ${ }^{1}$, Keiko Miura ${ }^{2}$, Hiroo Yokozeki, Kazumoto Katagiri ${ }^{1}$ \\ Department of Dermatology, Graduate School of Medical and Dental Sciences, Tokyo Medical and Dental University Graduate School, \\ Tokyo, ${ }^{1}$ Department of Dermatology, Dokkyo Medical University Koshigaya Hospital, Saitama, ${ }^{2}$ Department of Pathology, Graduate \\ School of Medical and Dental Sciences, Tokyo Medical and Dental University Graduate School, Tokyo, Japan
}

\section{Dear Editor:}

Multiple basal cell carcinomas (BCCs) have genetic backgrounds as nevoid basal cell carcinoma syndrome (NBCCS), although multiple BCCs with unknown genetic backgrounds exist $^{1-4}$. Furthermore, cases of multiple BCCs with infundibular structures and trichoblastoma are quite limited $^{2,5}$. Here we present a novel case of multiple BCCs with trichoblastoma.

An 82-year-old female presented with a painful ulcerated black tumor on her left cheek. A black nodule on her left cheek had been recognized in 2010. She had no familial history of NBCCS. A physical examination revealed a $43 \times 40 \mathrm{~mm}$ ulcerated black tumor mass on her left cheek
(Fig. 1A). The patient also had seven 2 to $10 \mathrm{~mm}$ black nodules on her face and neck and two $3.5 \times 3 \mathrm{~mm}$ nodules on her back (Fig. 1B D). Histopathological examination of the tumor on her face showed tumor nests in conjunction with the epidermis. The tumor nests manifested infiltrative proliferative patterns (Fig. 1E). Each tumor nest was composed of basaloid cells. Some tumor nests were arranged in an anastomosing fashion (Fig. 1F). Immunohistochemistry revealed positive reactions for cytokeratin 14 (CK14), CK17, Ber-EP4 and $\mathrm{BCl}-2$ and negative reactions for CK20 and CD34. The diagnosis of BCC was made. Histopathology of the tumor on her cheek showed large tumor nests that extend into the deep dermis (Fig. 1G).

Received December 5, 2017, Revised March 28, 2018, Accepted for publication April 25, 2018

Corresponding author: Takeshi Namiki, Department of Dermatology, Graduate School of Medical and Dental Sciences, Tokyo Medical and Dental University Graduate School, 1-5-45, Yushima, Bunkyo-ku, Tokyo 113-8510, Japan. Tel: 81-3-5803-5286, Fax: 81-3-5803-0143, E-mail: tnamderm@tmd.ac.jp ORCID: https://orcid.org/0000-0002-1092-1159

Kazumoto Katagiri, Department of Dermatology, Dokkyo Medical University Koshigaya Hospital, 2-1-50, Minamikoshigaya, Koshigaya, Saitama 343-8555, Japan. Tel: 81-48-965-1111; Fax: 81-48-965-8927; E-mail: katagiri@dokkyomed.ac.jp ORCID: https://orcid.org/0000-0002-8303-6994

This is an Open Access article distributed under the terms of the Creative Commons Attribution Non-Commercial License (http://creativecommons.org/ licenses/by-nc/4.0) which permits unrestricted non-commercial use, distribution, and reproduction in any medium, provided the original work is properly cited.

Copyright (C) The Korean Dermatological Association and The Korean Society for Investigative Dermatology 

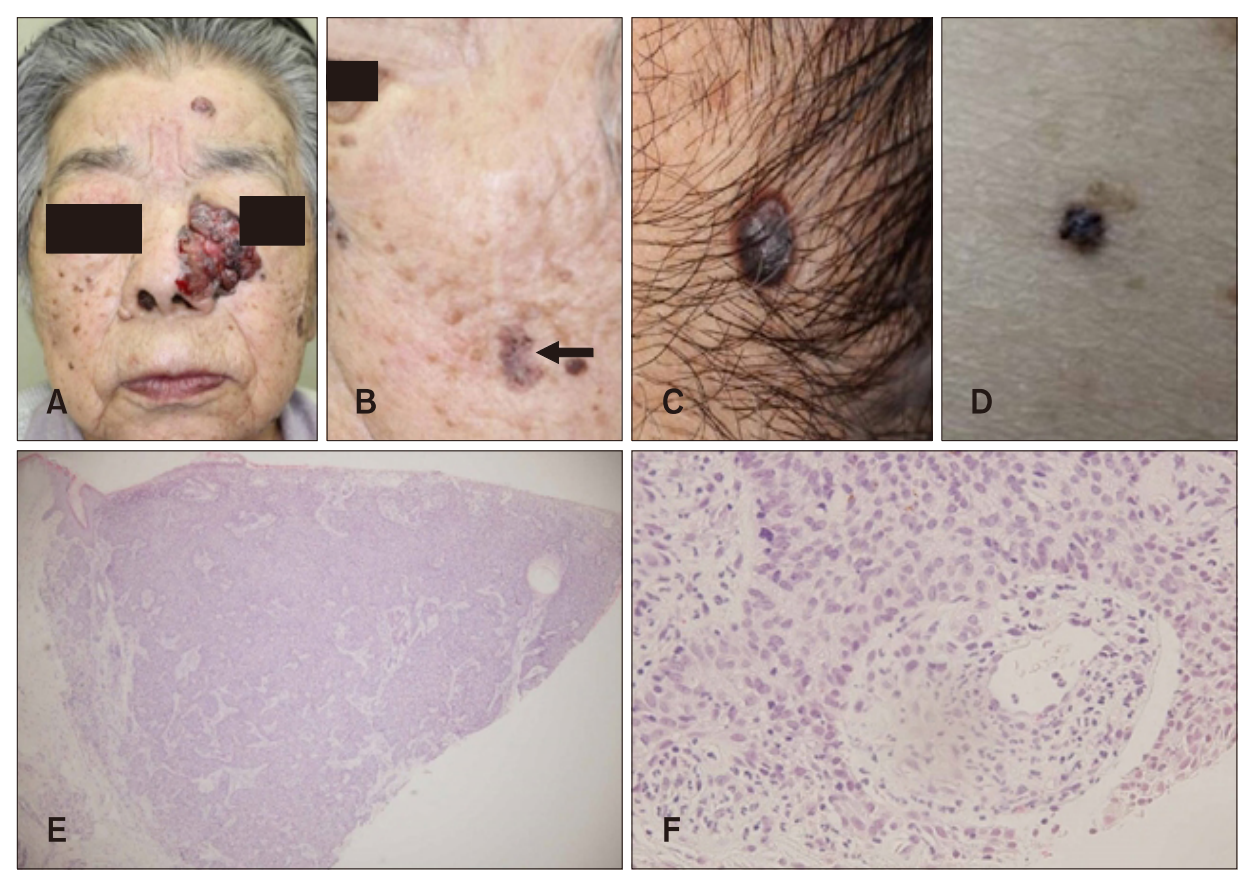

Fig. 1. (A) An ulcerated black tumor mass on her face. (B) A keratotic black nodule on her left cheek; the arrow indicates the lesion. (C) A black nodule on her neck. (D) A black nodule on her back. (E) Histopathology of the tumor on her face showing tumor nests extending to

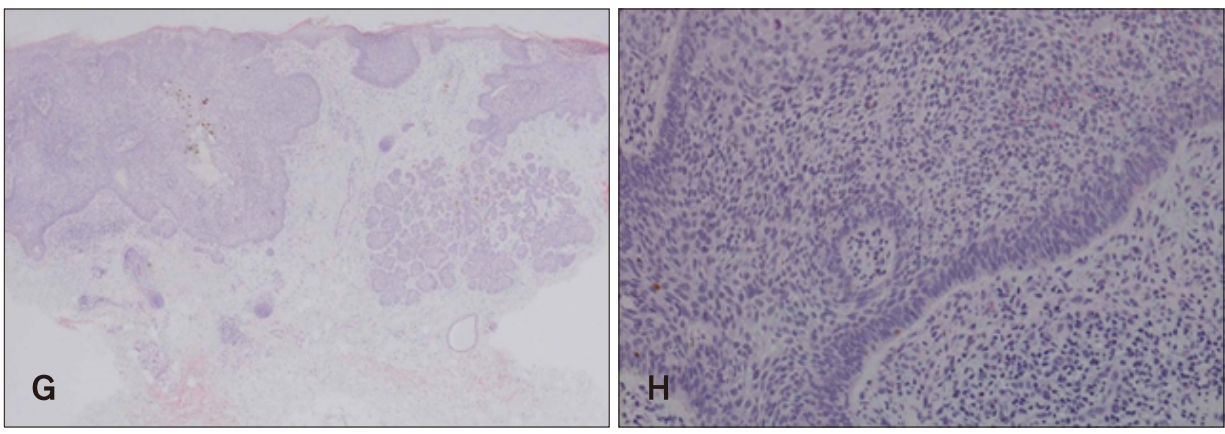
the subcutaneous tissue $(\mathrm{H} \& \mathrm{E}, \times 40)$. (F) Some tumor nests arranged in an anastomosing fashion $(\mathrm{H} \& \mathrm{E}, \times 200)$. (G) Histopathology of the tumor on her cheek showing large tumor nests that extend into the deep dermis $(\mathrm{H} \& \mathrm{E}, \times 40)$. (H) Each tumor nest showing a palisading arrangement $(\mathrm{H} \& \mathrm{E}, \times 100)$. We received the patient's consent form about publishing all photographic materials.
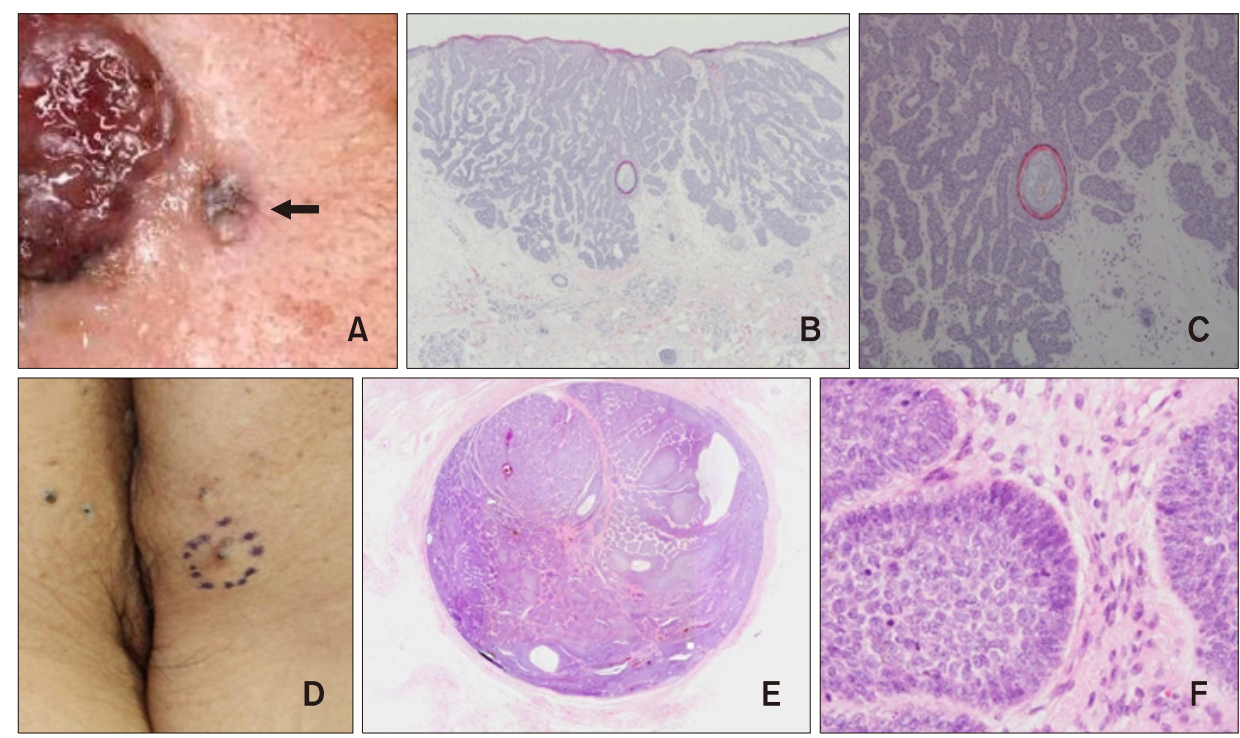

c

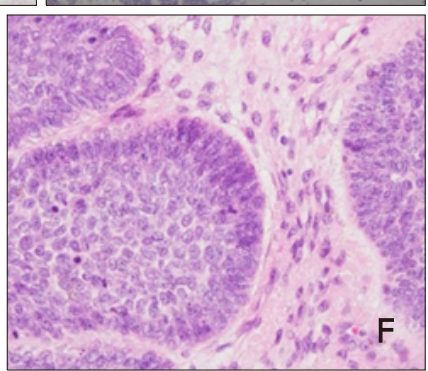

Fig. 2. (A) A nodule adjacent to the tumor mass on her left cheek; the arrow indicates the lesion. (B) Histopathology showing anastomosing tumor nests extending into the deep dermis in conjunction to the epidermis $(\mathrm{H} \& \mathrm{E}, \times 40)$. (C) Infundibular structures situated in the center of the tumor $(H \& E$, $\times 100$ ). (D) A subcutaneous tumor on her left buttock. (E) Histopathology showing a well-circumscribed tumor with a surrounding cleft in the deep dermis. No continuity of the epidermis and the tumor was found $(H \& E, \times 20)$. (F) Some of tumor nests showing a differentiation toward follicular structures $(H \& E, \times 400)$.
Each tumor nest showed a palisading arrangement (Fig. $1 \mathrm{H})$. Physical examination revealed a $5 \times 4 \mathrm{~mm}$ black nodule adjacent to the tumor mass (Fig. 2A). Histopathological examinations showed that anastomosing tumor nests extended into the deep dermis (Fig. 2B). Infundibular structures were situated in the center of the tumor (Fig. 2C). 
Immunohistochemistry revealed almost consistent results with the tumor mass. We considered this nodule as BCC with infundibular structures. A physical examination revealed a $15 \times 15 \mathrm{~mm}$ subcutaneous tumor on her left buttock (Fig. 2D). Histopathological examinations showed a well-circumscribed tumor with a surrounding cleft. No continuity between the epidermis and the tumor was found (Fig. 2E). Some of tumor nests showing a differentiation toward follicular structures (Fig. 2F). We considered this nodule as a trichoblastoma. We performed radiation with 60 Gy of the tumor mass on her left cheek.

Multiple BCCs include various expressions with benign and/or malignant neoplasms with follicular differentiation and some of them have been classified as hereditary diseases such as $\mathrm{NBCCS}^{1,2}$. The exact clinical entity and the etiology of various multiple BCCs have not been fully elucidated due to the limited number of cases. Our case was difficult to assign into an existing clinical and histopathological entity. However, multiple occurrences of both benign and malignant follicular neoplasms may imply shared genetic aberrations. Our case of multiple BCCs is also extremely valuable in terms of the association with trichoblastoma. Although an association of trichoblastoma with multiple BCC is rare, various expressions of follicular neoplasms from benign neoplasm to malignant neoplasms in our case may account for the occurrence of trichoblastoma in a case with multiple BCC. Accumulation of such cases should be important for the elucidation of multiple BCC.

\section{CONFLICT OF INTEREST}

The authors have nothing to disclose.

\section{ORCID}

Kohei Kato, https://orcid.org/0000-0002-0223-1545

Takeshi Namiki, https://orcid.org/0000-0002-1092-1159

Rana Kawai, https://orcid.org/0000-0003-1750-3950

Keiko Miura, https://orcid.org/0000-0001-9238-6067

Hiroo Yokozeki, https://orcid.org/0000-0002-5773-9485

Kazumoto Katagiri, https://orcid.org/0000-0002-8303-6994

\section{REFERENCES}

1. John AM, Schwartz RA. Basal cell naevus syndrome: an update on genetics and treatment. Br J Dermatol 2016;174: 68-76.

2. Schulman JM, Oh DH, Sanborn JZ, Pincus L, McCalmont $\mathrm{TH}$, Cho RJ. Multiple hereditary infundibulocystic basal cell carcinoma syndrome associated with a germline SUFU mutation. JAMA Dermatol 2016;152:323-327.

3. Ojevwe FO, Ojevwe CD, Zacny JP, Dudek AZ, Lin A, Kohlitz P. Treatment of multiple unresectable basal cell carcinomas from Gorlin-Goltz syndrome: a case report. Anticancer Res 2015;35:1777-1781.

4. Zheng LQ, Huang Y, Qu YJ, Zhang YH, Han XC. Multiple basal cell carcinomas arising in a verrucous epidermal nevus. J Dermatol 2013;40:482-483.

5. Requena L, Fariña MC, Robledo M, Sangueza OP, Sanchez E, Villanueva A, et al. Multiple hereditary infundibulocystic basal cell carcinomas: a genodermatosis different from nevoid basal cell carcinoma syndrome. Arch Dermatol 1999;135:1227-1235. 